\title{
How to Write a Philosophy Paper
}

David Jones, PhD; Timothy O’Neill, MA; and Brendan Shea, $\mathrm{PhD}$

Rochester Community and Technical College

Writing a high-quality philosophy paper requires somewhat different skills than writing papers in other disciplines. In particular, you'll need to think about the following three things:

1. How to read and understand the philosophical texts that you'll be responding to in your paper.

2. How to formulate successful arguments, and give objections to the arguments of others.

3. How philosophy papers will be evaluated, and how this might differ from what you are used to.

This short guide will provide step-by-step guidance to each step of the process. How you use it is up to you. For example, your instructor may recommend that you read this guide in its entirety, either before you write a paper, or once you are in the process of revising a rough draft. Alternatively, if you have a question about a particular aspect of writing philosophy papers, you can jump right to that section.

\section{Contents:}

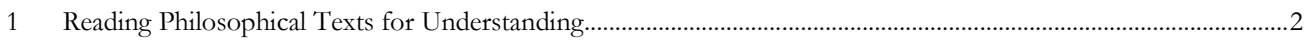

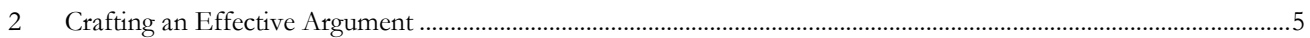

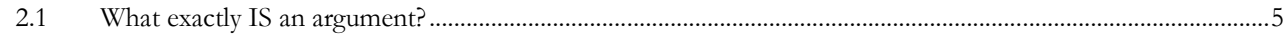

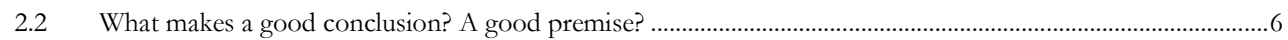

$2.3 \quad H o w$ do I respond to arguments from other philosophers? ...................................................................................

$2.4 \quad$ What is the role of definitions in philosophical argumentation?

2.5 How does evidence work in philosophical arguments? .............................................................................

$2.6 \quad$ What separates strong arguments from weak arguments?

2.7 What's fair game? How to ensure your premises are relevant .................................................................................11

2.8 The Dos and Don'ts of Arguing: A Summary ……………………………...................................................13

3 General Grading Criteria for Philosophy Papers .............................................................................................13

3.1 Argument Form.....................................................................................................................................13

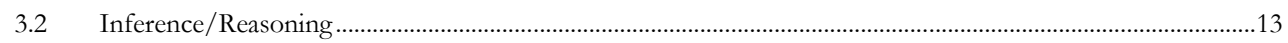

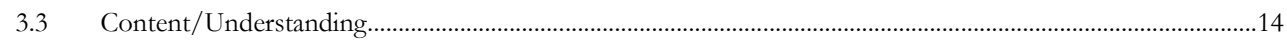

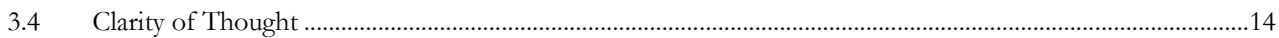

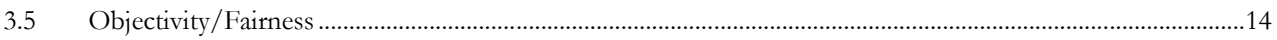

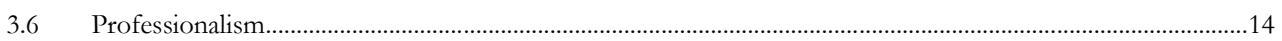

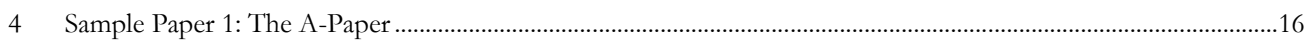

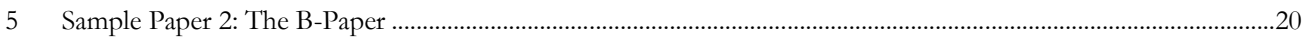

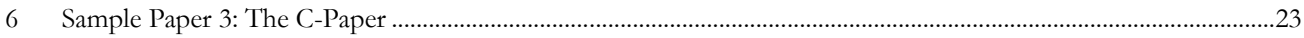




\section{Reading Philosophical TeXts for Understanding}

Philosophy can often be tough to read, and not just for beginners. Even professors will struggle with at least some texts, especially if they are reading the philosopher for the first time. Part of this is because philosophy courses often require you to read the original works rather than secondary works, like textbooks. So, the reading in philosophy courses is like that in Literature courses in requiring you to read originial works, and like courses in the natural and social sciences in reading for argument and explanation rather than narrative.

Philosophy can also be frustrating, even infuriating, to read because we are sometimes confronted with views very different from our own, and which sometimes call some of our most strongly-held beliefs into question. So don't be surprised if you sometimes find yourself confused by what you read, or reacting strongly to it. Even the best students find themselves going through this.

As with other subjects you're studying, you'll find that it's regular practice that helps best understand the material. However, knowing a bit about what distinguishes philosophical writing from some other kinds, and knowing what to aim for when reading philosophy, can make the practice more productive. The tips below can help you feel more confident in approaching the reading in your philosophy course.

\subsection{The PrEliminaries FOR READING:}

Acknowledge that reading well is the most important thing you do in your philosophy course. Having your own ideas about the issues is great; recognizing the main conclusions reached on different topics is good. However, the heart of understanding philosophy is reading it well. You simply won't do especially well if you don't read the material with care.

Minimize distractions. Philosophy involves abstract concepts and demands your undivided attention. Lock yourself away from friends and family and kill the T.V., radio, Facebook, cell phone, etc. Use Goddard Library, if you can.

Read early. Read often. Get an early start: you may need more time than you thought or you may need to reread it. This is not uncommon.

Read slowly. The ideas and writing can be difficult, understanding the details is essential to doing well, so take your time.

Read actively. Write marginal notes and/or underline or highlight important passages. Bring these highlights and questions into class discussion. If you are concerned about the resale value of your books, consider writing lightly in pencil or using a reading journal.

Take breaks as you read. At the end of a section, consider what you have read. Take short breaks even if you are not finished with an article: research shows that comprehension drops dramatically after 30-45 minutes of steady reading.

\subsection{WHAT TO KEEP IN MIND WHEN READING:}

Philosophy has its own terminology. Like physics or art history, philosophy is a specialized field with its own set of terms, which will sometimes be unfamiliar to you. Keep this in mind when something is unclear to you. The philosopher isn't trying to be unclear, any more than physicists are. What can sometimes make cause problems is that some terms in philosophy are the same as others found in other fields or everyday life, but have different meanings in philosophy. If a passage doesn't make sense to you, use a dictionary. Pay attention to every word. Look up unfamiliar terms and confirm that words make sense in context. If you think a word is being used in a technical, philosophical 
sense, check the online Stanford Encyclopedia of Philosophy or ask your instructor. Never skip an unfamiliar word in philosophy - every word matters.

Philosophical writing consists primarily of arguments in support of a major conclusion.

You always want to keep in mind that the aim of any philosophy you are reading is to rationally convince you to accept the main conclusion of the essay, book, etc. You are reading an attempt to persuade you of a conclusion. This is different from, say, a novel, which (usually) isn't trying to persuade you of something particular. While philosophy papers can include stories ("thought experiments") or historical accounts, they are never the point of what you are reading. It's also different from reading science textbooks, where the aim is to explain facts, theories, and concepts.

The best way to spot arguments is by looking for argument indicator words:

- Words or phrases such as, "therefore"; "thus"; "hence”; "so"; "in conclusion”; “consequently"; "showing that"; "demonstrating that"; "proving that"; "establishing that"; "meaning that"; "entails that"; "implies that"; "as a result" often indicate a conclusion.

• Words or phrases such as "because"; "as"; “since”; "in order to"; “otherwise”, "First,...", “Second, ...”, "Third, ..." etc., indicate reasons.

- Words or phrases such as "some might argue that" or "it has been suggested that" may indicate a counterargument.

Arguments will be put forward that the writer doesn't accept herself, so it can seem like she's contradicting herself. Philosophical writing is an attempt to show that a particular conclusion is true using argument. We have better reason to accept a conclusion if we can see reasons both for accepting it and reasons for rejecting alternative conclusions. So philosophical writing often discusses and responds to objections someone might have to the conclusion being supported. For example, if her conclusion is that we should be willing to help strangers far away from us as much as we are willing to help those close to us, then a philosopher will need to answer the objection that it's thought acceptable to favor our families and friends. She is likely to do this by first explaining the "family and friends" objection and then attempting to show why that objection doesn't show her conclusion to be wrong.

Philosophical writing can seem repetitive, but the repetition has a point.

First, be sure that what you are reading really does repeat what's already been said. Often what seems like repetition isn't. It's where a smaller argument is being made to support a larger conclusion, or it's where an objection is being raised or responded to. Slow, careful reading should make it clear what's going on. It is common in philosophical writing for the writer to repeat her main points and conclusion(s). This is done to make the flow of the arguments clearer for the reader. After listing examples or answering objections, it's often helpful to restate where the arguments are meant to take the reader.

\subsection{The NeCESSARY StePs FOR EFFECTIVE READING}

\section{Set the context}

Before trying to understand the details of what you're reading, spend a bit of time getting the basic background.

- Who wrote the piece and when? (Personalizing the writer helps you remember what was argued.)

- What does the title imply will be the main conclusion of the piece? 
- Look at the chapter or section headings. Remember that the piece consists (more or less) of major and subarguments in support of a major conclusion. The writer has divided the piece to make the structure of these arguments and sub-arguments clearer.

- Find the thesis or main conclusion and state it in your own words. Try not to confuse the thesis statement, which says what the author is trying to show, with focal statements, which say what issue(s) the author will discuss.

- Try to find the main argument(s) the author uses in support of her major conclusion

\section{Map the territory}

Now that you have a general idea of what the author is trying to show and how, do a first careful reading of the piece, aiming to lay out the structure of the arguments. Good philosophical writing will (often) have a sort of building-block structure where the conclusion is supported by one or more major arguments, and these are supported by other arguments.

- Try to name or number the arguments you find in the text.

- Try to diagram how these arguments relate to one another and to the major conclusion.

- Make note of arguments or points you think particularly strong, unclear, or wrong. (These will be used in the next step.)

\section{Stake your claim}

The aim of your final reading of the material should be to see whether you think the author is right or wrong (or perhaps partly right and partly wrong). Here you are finding out where you stand with regard to the reading. You should go back over the structure of the reading, focusing on those arguments and points that struck you previously, and looking for others.

- Look for where you agree and disagree with the author, making sure that you are interpreting what the author says in a reasonable way.

- See whether the points where you disagree with the author have anything in common. That is, try to figure out whether your disagreement is a broader one.

\section{Build your own.}

Your final step should be to begin writing informally with the aim of developing your own responses to the author.

- Drawing on the points and arguments you have disagreed with, try to write out why you think the argument is wrong. What reasons can you give for thinking it is? While writing, don't worry about grammar or spelling, just concentrate on getting your ideas down on paper. It's sometimes best to commit to doing this for a brief period - say 10-15 minutes, so the process doesn't seem too intimidating.

After following the guidance here you might still come away feeling confused about parts of what you've read. This is especially true where you are reading original philosophical writing. It's not something to worry about. There can be several reasons why you still don't feel you have a full understanding of the material even after doing thorough reading - difficult concepts, complex arguments, even just plain bad writing. (Your instructor usually weeds out examples of this last one, though.) Whatever the reason it's important not to see this as a problem. Bring up what's 
still puzzling you in class with your instructor. It's said in many fields, but is probably true in philosophy more than anywhere: your question isn't dumb. More often than not, if you've done thorough reading, you're puzzled because you've caught on to a real problem with the views you're examining. That's a good thing. You're puzzled because you are in the process of doing philosophy instead of being a passive spectator.

\section{Crafting AN EFFECTIVE ARgument}

Most (though not all) philosophy papers involve making an argument in favor of some position or other. A good paper is one that makes a strong, convincing argument (a sound or cogent argument, as philosophers might say). Conversely, a bad philosophy paper is one that either fails to make an argument, or offers a weak and unconvincing argument. While many of the issues discussed in philosophy classes lack clear, widely agreed upon solutions, this does not mean that all positions are "equal." Instead, when making an argument about philosophical issues, you'll be expected to demonstrate that you have thoughtfully and impartially thought about the evidence relevant to the issue you've chosen, and can provide an argument that your solution is the best one, all things considered.

Even when your argument falls a bit short of this high standard (as most arguments do!), the effort to make this sort of argument is a valuable learning experience. In particular, taking philosophical arguments seriously requires that we learn to differentiate between two different things: (1) our strong emotions about a particular issue and (2) the actual reasons we have for holding the position we do. This is not something that comes naturally to most of us, but it's critically important, both in helping us to understand those with whom we disagree, and in helping us improve and revise our own views. So, when writing arguments, remember that the goal is not (mainly) to win the argument, but learn something of value.

With this end goal in mind, let's consider some concrete suggestions for making strong arguments. These are presented in forms of common questions that students have about making arguments, together with the replies to these questions.

\subsection{WHAT EXACTLY IS AN ARGUMENT?}

Every argument involves two parts: a conclusion, and one or more premises that are intended to provide reasons to believe this conclusion. In other words, making an argument requires more than simply asserting that your conclusion is true, or telling the reader what you believe or feel. It requires giving reasons, in the form of premises. In good arguments, the premises really do support the conclusion; in bad arguments, the premises don't.

DO state your conclusion and premises clearly. Philosophy papers are, in essence, extended arguments. They introduce a problem, propose a conclusion, and offer premises in support of this conclusion. They also consider potential counterarguments that might be made against the conclusion. Each paragraph should do some definite chunk of argumentative "work," whether this be explaining the conclusion, providing support for a premise, answering an objection, etc.

Your conclusion should appear prominently in your thesis sentence, as should a brief summary of what sort of premises you'll be offering in favor of it. So, for example, a good thesis sentence might be: "I'll be arguing that physician aid-in-dying should be legalized, since it respects patient's autonomy." In the body of this paper, you'll probably want to begin by explaining what exactly autonomy is (see the next section for guidance of definitions), before moving to showing how and why a patient's autonomy supports your conclusion. While presenting your premises, you should keep your reader in mind: what things might be confusing to them? What might they be tempted to disagree with? When you are done, your reader should have a good idea of not only what you believe, but why you believe it. 
DON'T just say what you "believe," "think," or "feel." Perhaps because philosophy papers often involve issues about which we have strong opinions and emotions (religion, politics, morality, etc.), there is a tendency to simply tell the reader what you think, feel, or believe about the issue in question, and leave it at that. However, you should resist this temptation, since it defeats the whole purpose of philosophy papers, which is to offer an argument that is convincing to someone who doesn't share your initial emotional response to the issue under discussion. If you find yourself struggling to offer this sort of argument, you should at least consider the possibility that your initials beliefs, thoughts, or feelings about an issue might be leading you to an incorrect conclusion.

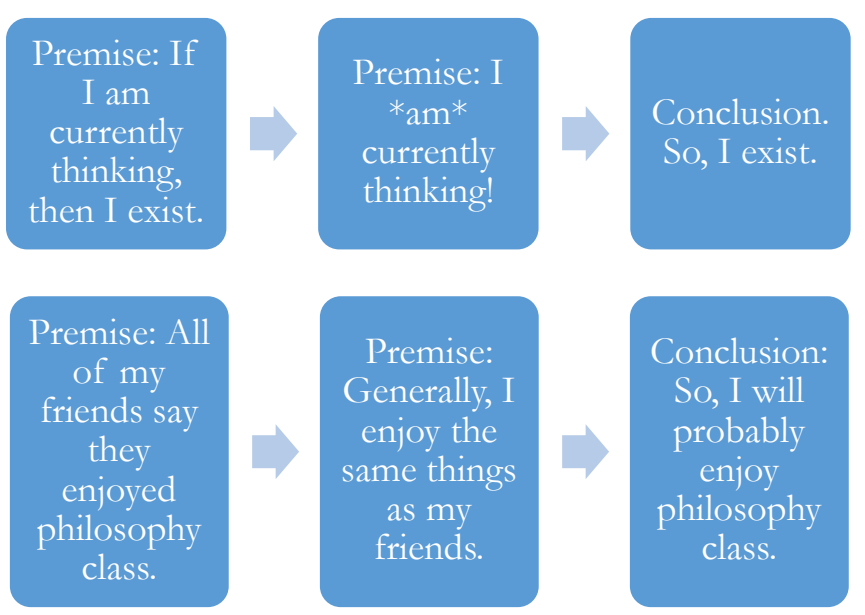

This is a deductive argument. If the two premises are true, there's no way the conclusion can be false.

This is an inductive argument. Even if your premises are true, you still might be wrong about your conclusion. However, this doesn't mean it's not a good argument!

\subsection{WHAT MAKES A GOOD CONCLUSION? A GOOD PREMISE?}

When making a philosophical argument, you should be defending an interesting conclusion about which reasonable might disagree. Your premises, by contrast, should be claim about which these same sorts of reasonable people all AGREE. Basically, your goal is to show your audience that they ought to believe your (interesting, debatable) conclusion because they accept the premises you offer. If they find the conclusion to obviously true, or if they find the premises you offer to be obviously false, the argument will fail to achieve its purpose.

DO use premises that your opponents would accept When you are writing a philosophical argument, remember that the goal is NOT simply to explain why you think a certain conclusion is true ("I think abortion is wrong, because fetuses have the same right to life as adult humans"). Instead, you need to support your conclusion with premises that people who initially disagree with your conclusion will be able to accept. This requires thinking hard about what you and your opponents actually agree on (e.g." "fetuses are biologically human") and showing why and how these areas of agreement provide reasons to believe your favored conclusion. (Again, if you are struggling to do this, consider whether your conclusion might need to be revised).

DON'T beg the question or offer a false dichotomy. An argument "begs the questions" if it relies on premises that opponents would not accept ("We ought to ban firearms [conclusion], since this would eliminate all violent crime [unacceptable premise]"). Similarly, an argument commits a "false dichotomy" when it offers a premise of the form: "either my view is right, or this [obviously crazy] other view is. Since this other view is false, my view is right!" (Here, the problem is that there are almost certainly other, more plausible views that haven't been considered.) These ways of 
arguing are very easy to fall into, especially when we are talking to people who we know agree with. However, they will fail to convince your opponents, and will often alienate them in the process.

\subsection{HOW DO I RESPOND TO ARGUMENTS FROM OTHER PHILOSOPHERS?}

Philosophy papers often spend quite a bit of time talking about the arguments of other philosophers. That is, they spend a lot of time trying to explain (1) what conclusion these other philosophers defend and (2) what premises these philosophers offer in support of it. The paper may then move on to offering additional support for, or arguments against, the views in question. Because of this, it's crucially important to think about the way in which you describe the views of others. In almost every case, you should remember that your goal is to describe the ARGUMENTS given by other philosophers, and not merely their conclusions. As a rule of thumb, if you say "Philosopher P believes X," you should also explain why P believes this.

DO follow the "principle of charity" when describing other people's arguments. The principle of charity states then, when you are interpreting someone else's argument, you want to give them the "benefit of the doubt" whenever this is possible. When summarizing their argument, you should always aim to make their premises sound as plausible as possible, and their reasoning comprehensible. The test should always be: If the person I'm writing about read my summary of their argument, would they agree with it? In some cases, this will be relatively easy, if the person you are discussing is an exceptionally clear writer. In other cases, however, this might be more challenging, for a variety of reasons. For example, the author might use a lot of technical language when expressing their argument, or they might simply be very emotionally invested in the issue. In these cases, it can be tempting to focus on the weaknesses in the author's presentation, especially if you happen to disagree with their conclusion. However, you should avoid doing this. Instead, you should aim to present the best possible version of this author's argument. Only then should consider moving on to the premises.

DON'T claim that an argument's conclusion is false before considering its premises. In almost every philosophy class, you'll encounter at least a few authors or ideas with which you strongly disagree. This is good! However, when writing your paper, you need to remember that your focus needs to be on reasons and arguments, and not (just) on what you feel, think, or believe about a conclusion. This means, for instance, that you are expected to explain why and how an argument with which you disagree goes wrong. This means focusing on the author's premises, and on their relationship to the conclusion. You might argue that a given premise is incorrect for example, or that the author failed to consider some relevant piece of evidence. Doing this successfully requires looking closely at how the author got to their position, and it requires putting aside (at least for a little while) your own thoughts about the ultimate truth or falsity of their conclusion.

\subsection{WHAT IS THE ROLE OF DEFINITIONS IN PHILOSOPHICAL ARGUMENTATION?}

Philosophical arguments often concerns concepts and ideas (like morality, personal identity, God, etc.) that different people understand in very different ways. Because of this, philosophical arguments often devote considerable time to offering clear, precise definitions of the relevant terms. This helps readers understand what exactly the conclusion is claiming, and how the premises are being used to support it. One can't, in general, assume that philosophers "mean the same thing" by their words as ordinary people do.

DO offer accurate definitions of key terms (and give examples). No matter what your philosophical topic happens to be-euthanasia, virtue ethics, methodological doubt, etc.—you should write as if your audience does NOT know about these concepts, and that it is your job to accurately and completely explain all of the ideas relevant to your argument. This means paying close attention to the details of the definitions offered in class and in the readings, and taking the time to show how these definitions might be applied to particular cases. You'll need to anticipate potential misunderstandings on the part of your readers or listeners, and find creative, original ways of 
helping them grasp exactly WHAT the idea in question is and WHY it matters. (This will also help YOU understand the definitions better.)

DON'T leave terms undefined, or use an ordinary dictionary to define them. In philosophy, the details of the definitions matter. Because of this, you should never assume that (1) your audience already "knows what you are talking about" or (2) you can safely use an ordinary dictionary (such Merriam-Webster) to define key terms. Instead, it's your job to define the terms in way that demonstrates your own understanding of what is going on in the reading or in class. In order to do this effectively, you should be able to explain the key terms and ideas in your own words, even with the book closed. If you can't do this yet, take some time and review this material.

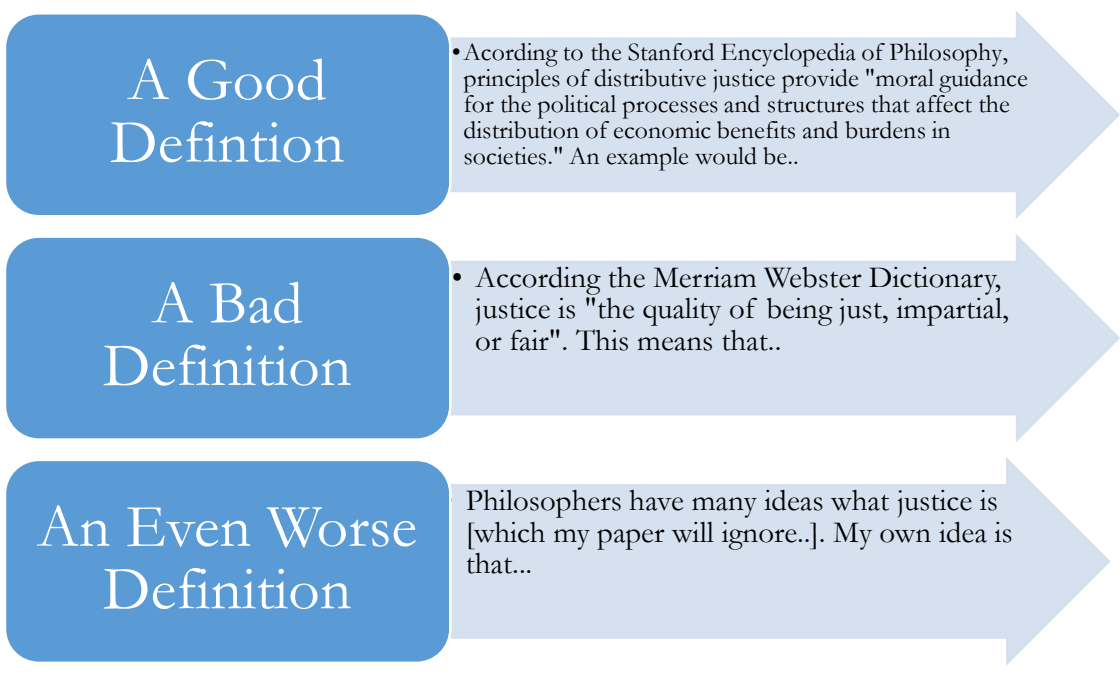

\subsection{HOW DOES EVIDENCE WORK IN PHILOSOPHICAL ARGUMENTS?}

Whenever you make an argument, you'll want to think carefully about what type of argument you are making. On the one hand, you might be trying to prove that your conclusion is true, with $100 \%$ certainly, at least on the assumption that your premises are true. Philosophers call doing this deductive argumentation. While these sorts of arguments are common in mathematics, we actually don't use them much in everyday life, or even (much) in philosophy papers. In a well-formed deductive argument, it is quite literally IMPOSSIBLE (can't even be imagined!) for the premises to be true and conclusion false. In other words: in a deductive argument, we should have just as much faith in the conclusion as we bave in the premises.

Deductive arguments usually occur only in certain sorts of contexts, and they often involve showing how a certain sort of mathematical/philosophical definition really does guarantee the truth of a certain conclusion. When making a deductive argument, it's crucial to pay attention to the argument's form, since even a small error in the way the argument is formulated can render it useless. A few of the most important deductive argument forms are as follows (this is NOT a complete list):

\section{COMMON DEDUCTIVE ARGUMENTS}

Modus Ponens If $\mathrm{P}$ is true, then so is Q. P really is true. So, Q is true.

Modus Tollens If $\mathrm{P}$ is true, then $\mathrm{Q}$ is true. But, $\mathrm{Q}$ is NOT true. So, $\mathrm{P}$ isn't true either. 


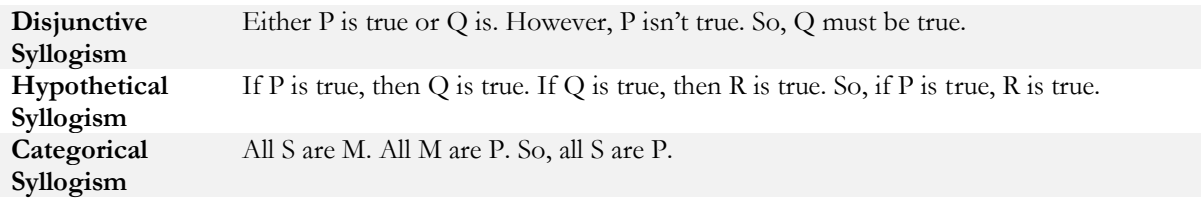

If someone makes a valid deductive argument, and you disagree with the conclusion, you have only one choice: you need to show that one of the premises is false. Conversely, once we know that the premise of a given deductive argument is false, the argument fails. For this reason, philosophers often use the tools of deductive argumentation to simplify and clarify both their own positions and the positions of those they disagree with. This helps make it absolutely clear to the reader what exactly their choices are, if they disagree with a particular conclusion.

While the black-and-white certainty of deductive arguments can be nice, many arguments in philosophy (and the vast majority of arguments in every day life) are actually forms of inductive argumentation, which involves the weaker claim that a conclusion is likely to be true, given the available evidence. This means granting up front that your conclusion might turn out to be incorrect, even if you are right about all of the premises. While this might seem like a very abstract idea, it has a practical consequence for paper writing: when making an inductive argument, you'll need to take care to show that you really have taken account of all of the relevant evidence, both FOR and AGAINST your position.

\section{COMMON INDUCTIVE ARGUMENTS}

Prediction Since $\mathrm{X}$ has happened in the past, it's likely to happen in the future.

Generalization Since X has happened in most (or all) observed cases, it will hold in most/all unobserved cases.

Causal Because $\mathrm{Y}$ regularly occurs right after $\mathrm{X}$ does, $\mathrm{X}$ is probably a cause of $\mathrm{Y}$ (or $\mathrm{Y}$ is an Argument effect of X).

Argument from Since a certain person, book, website, newspaper said that X is true, X really is true.

Authority

Analogical Since $\mathrm{X}$ and $\mathrm{Y}$ are similar in ways A, B, and C, they are probably similar with respect Argument to D as well.

Scientific A certain hypothesis or theory has made lots of successful predictions. So, this theory arguments is most likely true.

Statistical A high percent of things that are $\mathrm{X}$ are also $\mathrm{Y}$. This particular thing is an $\mathrm{X}$. So, it is syllogism probably also a Y.

There are good, bad, and mediocre examples of all of these sorts of arguments, and you'll need to look carefully at the content (and not just the form) to figure out which is which. When making an inductive argument, you want to show that the available evidence makes it more likely than not that your conclusion is true. In the next section, we'll discuss some common fallacies of weak induction, which can sometimes lead us to make bad arguments.

DO determine whether your argument is deductive or inductive. When writing a philosophy paper, you need to make it absolutely clear to both the reader (and yourself) what you are trying to do in making your argument: Are you trying to prove that it is immoral to eat meat? Or are you simply trying to say that this is the conclusion best supported by our available evidence?. If you are trying to give a deductive proof, you'll need to make sure that each step of your argument follows with $100 \%$ certainty from the last step ( $99.99 \%$ isn't enough!). For an inductive argument, your goal is simply to show that your conclusion is probably true, given ALL of the relevant evidence.

A simple test for the inductive/deductive distinction might be as follows: Can you imagine a world where (1) all of your premises are true but (2) your conclusion is still somehow false? If you can, the argument is an inductive one. So, 
for example, let's say you want to argue that animals like pigs and cows feel pain. Your premises in support of this conclusion involve the fact that the brain scans show that these animals have nervous systems similar to humans, and that they react in similar ways to things like cuts and burns (by making loud noises, etc.). This is an inductive argument, since it is possible (though very unlikely!) that your premises are true, but that the conclusion is false. So, for example, you can't deductively prove that humans' ability to feel pain is actually a result of their having opposable thumbs, which pigs and cows lack. While this is certainly an incredibly unlikely conclusion, given everything we know about the brain, the fact that we can imagine it shows the argument is inductive.

DON'T demand that your opponents “prove” you are wrong. If you aren't careful about distinguishing between inductive and deductive arguments, it can be easy to fall prey the appeal to ignorance, which occurs when you ignore all of the (inductive) evidence against your conclusion, and declare that, since your opponent has failed to (deductively) prove that you are wrong, your conclusion is probably true. So, for example, "I realize that you've given all sorts of reasons to think that I'm not being spied on by aliens. However, since you can't PROVE that this isn't happen, I'm going to keep believing it.”

The appeal to ignorance is very tempting, especially when it relies on our hopes or fears: "no one can prove thirdtrimester fetuses feel pain, so it's morally OK to have abortions in these caes" or "it's always possible that allowing more immigrants will lead to the collapse of society, so we shouldn't let them in," and so on.

\subsection{WHAT SEPARATES STRONG ARGUMENTS FROM WEAKARGUMENTS?}

Determining the validity or invalidity of deductive arguments is a challenging and technical task, and is one of the main topics covered in classes in philosophical or mathematical logic. Luckily for you, however, deductive arguments play only a small role in philosophy papers. Instead, the vast majority of work is done by inductive arguments, which can be either stronger or weaker, depending on how well the premises you give actually support your conclusion.

DO obey the principle of total evidence. When making an inductive argument, the important thing to remember is the principle of total evidence: it's your job to weigh and balance all of relevant evidence both FOR and AGAINST your chosen conclusion. This means you'll need to not only offer premises that support your conclusion, but also take to the time to explain and respond to evidence that seems to tell against your hypothesis. This doesn't mean you to include absolutely everything that anyone's ever written about your topic, since this would clearly be impossible. Instead, it simply means that you shouldn't attempt to hide or exclude the existence of things that you know might weaken your argument.

Different inductive arguments require different sorts of evidence. For example, when you are trying make a generalization, your goal is to show to establish something about a certain group (called the population). So, for example, perhaps you are trying to that most people in the U.S. would favor strengthening (or weakening) gun control laws in a particular way. In support of this conclusion, your premises might concern surveys that had been done about both this issue, and on similar issues. To the extent that these surveys had large, varied samples, this could be very good evidence in support of your conclusion. By contrast, you'd want to avoid appealing to anecdotal evidence, such as the opinions of your family or friends, or stories about individual people in the news. After all, you have no reason to think that these small, nonrandom samples are representative of the population as a whole. For similar reasons, it's important to consider the results of surveys and studies that might provide evidence against your conclusion, as well as those that support it. For example, it's not OK to cite the results of a survey that support your views on gun control while leaving out the results of a different survey that support your opponent's view.

DON'T commit a fallacy of weak induction. In general, a fallacy which occurs when there is something wrong with your reasoning besides simply being based on false premises. (That is, a fallacy involves making a mistake that you really ought to have been able to avoid. It's not just a matter of your not having complete information.) Many of the fallacies related to induction are closely linked to the general phenomenon of confirmation bias-that is, of our 
finding it much, much easier to "notice" the sorts of evidence that confirms what we already believe, as opposed to evidence that might suggest we need to change our ways. For this reason, it is often a good deal easier to recognize when other people (especially those we disagree with) are committing fallacies than when we ourselves are.

\section{FALLACIES OF WEAK INDUCTION: DEFINITIONS}

\begin{tabular}{l|l}
\hline What it is & $\begin{array}{l}\text { In a small, unrepresentative sample with which I happen to be familiar, members of } \\
\text { group G are often S. So, most members of G are S. }\end{array}$ \\
\hline Slippery Slope & $\begin{array}{l}\text { If we allow A, B might happen. And if B happens, C might happen.... and so Z might } \\
\text { happen. Z would be really bad. So, we must prohibit A. }\end{array}$ \\
\hline $\begin{array}{l}\text { Arg. From Unqualified } \\
\text { Authority }\end{array}$ & $\begin{array}{l}\text { A biased or unqualified authority said that C was true. So, C probably is true. } \\
\text { Weak Analogy }\end{array}$ \\
\hline $\begin{array}{l}\text { Two cases are similar in some not-very-relevant respects. So, they are probably } \\
\text { similar in another way, as well. }\end{array}$ \\
\hline False Cause & A happened before B. So, A probably was the cause of B. \\
\hline Suppressed Evidence & $\begin{array}{l}\text { A particular piece of evidence E supports C. [No mention made of evidence that } \\
\text { supports C's falsity.] So, C is likely to be true. }\end{array}$ \\
\hline
\end{tabular}

To get a better sense of how these fallacies work, here are some examples:

\section{FALLACIES OF WEAK INDUCTION: EXAMPLES}

\begin{tabular}{l|l}
\hline Hasty Generalization & $\begin{array}{l}\text { My cousin and I had a bad experience with Green Bay Packers fans one time. I also } \\
\text { saw a news story about some Green Bay fans who got thrown out of game. }\end{array}$ \\
\hline Slippery Slope & $\begin{array}{l}\text { If I don't Sam's text in the next half hour, he won't be my friend anymore. And if he } \\
\text { isn't my friend, I'll lose the rest of my friends, and will die miserable and alone. So, } \\
\text { I'd better return his text right now! }\end{array}$ \\
\hline $\begin{array}{l}\text { Arg. From Unqualified } \\
\text { Authority }\end{array}$ & $\begin{array}{l}\text { A random website I found said that people who are declared brain dead frequently } \\
\text { recover. So, this really happens. }\end{array}$ \\
\hline Weak Analogy & $\begin{array}{l}\text { Both Albert Einstein and Adolf Hitler were German vegetarians who had } \\
\text { mustaches. Einstein was also great physicist. Given this, it's likely that Hitler was } \\
\text { probably a skilled physicist. }\end{array}$ \\
\hline False Cause & $\begin{array}{l}\text { On any given day, people who go the hospital are much more likely to die than those } \\
\text { who just stay home. So, it's likely that hospitals are a major cause of death! }\end{array}$ \\
\hline Suppressed Evidence & $\begin{array}{l}\text { The earth looks flat. So, it actually is flat. [Suppresses evidence of the earth's } \\
\text { roundness.] }\end{array}$ \\
\hline
\end{tabular}

As with most fallacies, it is much easier to recognize these when other people (especially those with whom you disagree) commit them than when you yourself do. So, for example, to supporters of gun control, it may just seem obvious that guns lead to increased murder rates - after all, just think about how many murders are committed with guns! To opponents of gun control, however, different things may seem equally obvious-for example, that that gun control laws wouldn't actually prevent these murders (either because the murderers would buy guns illegally, or because they would just use knives).

In order to avoid fallacious inductive reasoning, you should focus on (1) starting with evidence that is acceptable to your opponents (e.g., statistics from impartial experts) and (2) carefully explaining out why and how this evidence supports your view, in a way that acknowledges (and provides responses to) the sorts of worries that your opponents will likely have. This doesn't mean, of course, that you'll always "win" the argument, or that you'll succeed in changing everyone's mind. However, to the extent that you rely on fallacious reasoning when making your case, your opponent won't really have any reason to take your argument seriously.

\subsection{WHAT'S FAIR GAME? HOW TO ENSURE YOUR PREMISES ARE RELEVANT}

In the previous section we looked at fallacies of weak induction, which occur when you overestimate the strength of your evidence. However, not all fallacious reasoning works like this. In other cases, a fallacious argument many 
involve premises that actually aren't relevant to the truth of your conclusion at all. Instead, these fallacies take advantage of aspects of human psychology_our fears and hopes, our desires to "belong" and to "win" arguments and to "save face" - in order to trick us into accepting conclusions without enough proof. With this general ideas in mind, it's worth spending some time thinking about those times when it's OK to "go with your gut" and when it isn't.

DO use your considered judgement about what's right and wrong. When writing a philosophy paper, it's perfectly OK to simply state your intuitions or judgments about certain issues, so long as your opponent will share them. For example, it's perfectly fine (at least in most contexts) to assert things like "lighting cats on fire for fun is wrong" or "if you can save a baby from drowning with little effort, you ought to do so." In these sorts of cases, your immediate emotional responses ("that sort of thing is clearly wrong!") can be a helpful guide, and its fine to simply state them. However, whenever you are tempted to make these sorts of claims, you need to keep in mind your audience: Would your opponent agree with this premise? If he or she wouldn't, then you'll need to back up and give an argument for the truth of your premise, even if you happen to find its truth to be obvious.

DON'T commit a fallacy of relevance. A fallacy of relevance occurs when the premises you offer in support of a certain conclusion aren't actually relevant to its truth. These fallacies occur because our reasons for believing in certain things (especially big, important things, of the sort we often deal with in philosophy) don't have nearly as much to do with reason or evidence as we would like to believe. The problem, of course, is that these fallacies are highly unlikely to convince those who don't already agree with us.

Here are some of the more common fallacies of relevance, some of which you might recognize from earlier on.

FALLACIES OF RELEVANCE: DEFINITIONS

\begin{tabular}{|c|c|}
\hline Ad Hominem & $\begin{array}{l}\text { Person } \mathrm{P} \text { is a hypocrite, liar, or is otherwise a bad person. Therefore, we can ignore } \\
\text { the argument they have given for/against } \mathrm{C} \text {. }\end{array}$ \\
\hline Appeal to the People & $\begin{array}{l}\text { Believing C will make it much easier for me to be accepted by my family, friends, } \\
\text { social group, or people in general. So, C is probably true. }\end{array}$ \\
\hline Appeal from Ignorance & $\begin{array}{l}\text { You haven't deductively proven to me that } C \text { is false. So, it's still reasonable for me } \\
\text { to believe that } C \text { is true. }\end{array}$ \\
\hline Appeal to Nature & Behavior $\mathrm{B}$ is natural. So, behavior $\mathrm{B}$ is morally $\mathrm{OK}$. \\
\hline Straw Man & $\begin{array}{l}\text { A misrepresentation of a certain argument for C doesn't work. So, the real argument } \\
\text { for C doesn't work either. }\end{array}$ \\
\hline Appeal to Pity & C being false would make certain people or groups upset. So, C is true. \\
\hline
\end{tabular}

FALLACIES OF RELEVANCE: EXAMPLES

\begin{tabular}{l|l}
\hline Ad Hominem & $\begin{array}{l}\text { Alec argues that marijuana should be illegal because it would raise lung cancer rates. } \\
\text { But I saw him smoking marijuana last night! So, his argument is obviously a bad one. }\end{array}$ \\
\hline Appeal to the People & $\begin{array}{l}\text { Everyone I know would think I was strange if I stopped eating meat. Therefore, } \\
\text { eating meat is morally OK. }\end{array}$ \\
\hline Appeal from Ignorance & $\begin{array}{l}\text { Biologists will never able to mathematically prove that humans and chimpanzees share } \\
\text { a common ancestor. So, I guess there will always be room for reasonable } \\
\text { disagreement about this issue. }\end{array}$ \\
\hline Appeal to Nature & $\begin{array}{l}\text { I read that humans are biologically wired to be violent to outsiders. So, I guess this } \\
\text { means that this sort of violence is morally OK. }\end{array}$ \\
\hline Appeal to Pity & $\begin{array}{l}\text { I heard Cali is pro-life. [I haven't paid any attention to her argument, but...]. She } \\
\text { must think that contraception is wrong, too. And this is clearly crazy! So, we can } \\
\text { dismiss her argument. }\end{array}$ \\
\hline $\begin{array}{l}\text { Deirdre would be devastated if she were fired-she just got divorced last month. } \\
\text { Therefore, your evidence that she's likely been stealing money from the company for } \\
\text { the last five years should be ignored. }\end{array}$ \\
\hline
\end{tabular}




\subsection{The Dos And Don'TS OF ARguING: A SumMARY}

We covered a number of "Dos" and "Don'ts" of effective argumentation. To help you remember, here is a brief summary:

\begin{tabular}{l|l} 
DO This & DON'T do this \\
\hline $\begin{array}{l}\text { DO state your conclusion and premises clearly. } \\
\text { DON'T just say what you "believe," "think," or } \\
\text { "feel." }\end{array}$ \\
\hline $\begin{array}{l}\text { DO use premises that your opponents would accept } \\
\text { describing other people's arguments. }\end{array}$ & $\begin{array}{l}\text { DON'T beg the question or offer a false dichotomy } \\
\text { DON'T claim that an argument's conclusion is false } \\
\text { before considering its premises. }\end{array}$ \\
\hline $\begin{array}{l}\text { DO offer accurate definitions of key terms (and } \\
\text { give examples). }\end{array}$ & $\begin{array}{l}\text { DON'T leave terms undefined, or use an ordinary } \\
\text { dictionary to define them. }\end{array}$ \\
\hline $\begin{array}{l}\text { DO determine whether your argument is deductive or } \\
\text { inductive }\end{array}$ & $\begin{array}{l}\text { DON'T demand that your opponents "prove" you } \\
\text { are wrong. }\end{array}$ \\
\hline $\begin{array}{l}\text { DO obey the principle of total evidence. } \\
\text { DO use your considered judgement about what's } \\
\text { right and wrong. }\end{array}$ & DON'T commit a fallacy of weak induction. \\
\hline
\end{tabular}

\section{General Grading Criteria for Philosophy Papers}

This list of criteria is designed to give you an overview of common expectations for philosophy papers. These criteria are not exhaustive, and your professor may give priority to some criteria over others, so always check with your instructor for standards and grading rubrics.

\subsection{ARguMENT ForM}

Argumentative philosophy papers should contain an easy to follow, logical argument. An argument is a series of statements in which some (premises) claim to support another (conclusion). Good logical structure helps lead your reader to adopt your conclusion. Formally, your paper should contain:

- a strong thesis paragraph that

$\circ$ establishes the importance of the topic/issue

o takes a clear, unambiguous position (thesis)

$\circ$ previews your reasoning in support of the position

- a body of supporting paragraphs that

$\circ$ contain clear topic sentences that provide a reason to adopt your thesis

$\circ$ provides additional support for the reason

- a strong counter-argument that

$\circ$ takes a position against/makes criticism of your argument (e.g. your position or reasons)

$\circ$ contains its own good reasons

0 includes a reply to the criticism showing why it fails

- a brief conclusion summarizing your argument

\subsection{INFERENCE/REASONING}

Do not assume that your reader agrees with you. Your job is to persuade. Whether your reader adopts your position depends, to a great extent, on the reasons you give. Your reasons should:

- clearly support your thesis

- be self-contained in well-formed paragraphs that 
- expand on the topic sentence/reason, explaining why it is good

- strengthen the inference between your premises and your conclusion

- be justified, where necessary, according to philosophical principles, concepts, and theories

- be explicit so as to avoid assumptions and rhetorical questions (e.g. "Who's to say what's right?")

- it is not enough to say what you or someone else believes (e.g. "it is right to maximize pleasure and minimize pain”); explain why your reader should agree with that belief (e.g. "... because any being that suffers has an interest in not suffering")

- avoid logical fallacies_ — common errors in reasoning that seem persuasive, but lack logical force.

\subsection{CONTENT/UNDERSTANDING}

You can only persuade a reader if she understands what you write, and you cannot do this unless you understand what you write. Before a single keystroke, read carefully, think critically, and compose your thoughts. An understandable argument will:

- include and explain key concepts and principles from the course and the topic

- define technical terms - philosophy uses ordinary terms in discipline-specific ways (e.g. "utility")

- accurately represent the thoughts, positions, and arguments of other people

- avoid using someone's words "out of context" to express something other than was intended

- properly cite, seamlessly integrate and, if necessary, explain direct quotations

- show insight through original examples and analogies

\subsection{Clarity of Thought}

The best arguments use language that is easy to understand. Many students want to impress the reader with their massive vocabulary, but this "purple prose" can lose your reader. A clear argument will:

- be concise

- do not fluff your paper (e.g. do not fill space with useless words to extend paper length)

- use ordinary language whenever possible, clarifying technical terminology as they arise

- be consistent

- do not skip between conflicting theories, conflate ideas (i.e. taking two different ideas to be the same idea), or equivocate (i.e. using the same term in different ways)

- obey rules of grammar

\subsection{OBJECTIVITY/FAIRNESS}

Your arguments should be self-critical. While you are being asked to take a position in an argumentative paper, if you unfairly present your case, it will weaken your argument. A fair argument will:

- $\quad$ keep personal biases in check

- consider likely objections to your position, and support them with strong counter-argument(s) that - accurately present opposing positions

- the principle of charity suggests that we give opposing perspectives a fair reading

include good reasons in support of the criticism, and

- explain why-even though the counter-argument is persuasive-it nonetheless fails.

\subsection{Professionalism}

You should present your argument in a clean, and professional manner. Your paper should:

- be free of typographical, formatting and grammatical errors

- avoid colloquial language and overly casual style

- follow all instructions are meet all requirements 



\section{SAmple Paper 1: The A-PAPer}

\section{Excellent Student}

Ethics PHIL 1125-01

Professor Awesome McAwesomeness

\section{Coffee and Drowning Children}

People are dying and you can stop it from happening. In Famine, Affluence, and Morality, Peter Singer argues that the current line that we draw between duty and charity is incorrect. Because our actions in the world affect human lives. If we are capable of meeting the needs of the poor without jeopardizing our own welfare, then we are obligated to do so. This obligation or duty to the poor is based on the principle of utility, and it is not affected by proximity or the existence of other people with a similar duty. The standard Singer sets flips our common conception of justice on its head.

Singer's argument is deceptively simple. It starts with "the assumption that suffering and death from lack of food, shelter, and medical care are bad." (266) Singer takes this premise to be blatantly obvious. Any being that has the capacity to suffer has an interest in not suffering. This is the foundation of the principle of utility—-that the absence of pain is universally good. To test whether this is the case, one need only hit oneself in the shin with a hammer. Singer's second premise states that, "if it is in our power to prevent something bad from happening, without thereby sacrificing anything of comparable moral importance, then we ought, morally, to do it." (266) It is a common belief that our moral duty is tied to the consequences of our actions. To the extent that we are able (i.e. "it is in our power") to stop something bad from happening, and having identified bad things with suffering and death from lack of food, shelter, and medicine, then we ought to do it, and we are wrong to not do so. The principle of utility, or the greatest happiness principle, holds that "actions are morally right in proportion as they tend to promote happiness; wrong as they tend to produce the reverse of happiness. By happiness is intended pleasure and the absence of pain; by unhappiness, pain and the privation of pleasure" (Mill 10).

To illustrate our duty to the poor, Singer gives the metaphor of a child drowning in a wading pool. It would cost you very little to save the child compared to what the child and everyone she loves stand to lose if she dies. There is no moral comparison between wet pants or muddy shoes and a human life. Since it is in my power to save the
Commented [TO1]: Professionalism: follows all instructions and meets all requirements.

Commented [TO2]: Argument Form: establishes the importance of the topic.

Commented [TO3]: Argument Form: takes a clear, unambiguous thesis position.

Commented [TO4]: Argument Form: previews reasoning in support of thesis.

Commented [TO5]: Argument Form: body of supporting paragraphs contain clear topic sentences

Commented [TO6]: Content/Understanding: properly cited

Commented [TO7]: Content/Understanding: direct citations are accurately represented and explained.

Commented [TO8]: Content/Understanding: includes and explains key concepts and principles.

Commented [T09]: Content/Understanding: shows insight through original examples.
Commented [T010]: Inference/Reasoning: justifies reasons by reference to philosophical principles, concepts and theories.
Commented [T011]: Inference/Reasoning: reasons are self-contained in well-formed paragraphs. 
child's life without, thereby, sacrificing something of comparable moral value, Singer suggests I am obligated to save

her. If I stand by and watch her drown, even though she has no other claim on my assistance, then I am morally wrong. Since the consequences alone matter for the moral worth of my action, and since I can stop this bad thing from happening, not helping the drowning child is morally equivalent to holding her head under water.

Some may argue that saving poor people on the other side of the planet is not the same as walking past a child in a wading pool. Of course it is wrong to let a child drown right in front of you, but this does not imply a duty to poor people far away from us. In the local case I can help because the drowning child is within reach; in the remote case, I cannot help because the victim is too far away. This reasoning is flawed, according to Singer, because proximity does not lessen the duty to stop something bad from happening, it just makes it less likely that one will help. It is psychologically more likely that someone will help a suffering person in front of the, but the basic principle that implies our duty to help is no different. With a click of the mouse, I can help relieve suffering. We walk past wading pools every day. In exchange for what I spend on my morning coffee, I can feed, shelter, and inoculate poor people. As much as I love coffee-and I do love coffee-the sacrifice of a single cup a day is trivial when compared to the life-saving utility that buck-and-a-half can purchase. I am, therefore, obligated to forego (at least) that cup of coffee so that I can send that money off to prevent bad things from happening.

It also doesn't matter how many people are standing around the pool. My moral obligation is the same regardless of if I am the only person who can help or if I am one of a million people similarly situated. If my action can prevent bad things without comparable moral sacrifice, then this is not contingent upon other people doing their duty. In fact, knowing that many people will ignore the drowning child (i.e. not send the coffee money to Oxfam), this creates a greater moral duty on me such that I ought to give more, because I know others are not living up to their duty and my increased aid can, therefore, relieve even more suffering, which is the morally right thing to do.

This flips the traditional model of the divide between charity and duty. It is commonly thought that we are obligated when someone is entitled to our help and that anything above this is supererogatory-above and beyond our duty. According to this standard, the threshold for duty is quite low. The standard proposed by Peter Singer makes actions previously thought of as charity moral duties. Take the cup of coffee example. The traditional model says that this is very generous; that the would-be donor would not have been morally wrong for buying a cup of
Commented [T012]: Inference/Reasoning: explicit argument; says why the reader should agree with the position.

Commented [T013]: Clarity of Thought: uses ordinary language.

Commented [T014]: Objectivity/Fairness: considers likely objections to the position.

Argument Form: takes a position against the argument.

Commented [T015]: Argument Form: strong counterargument contains its own good reasons.

Commented [T016]: Content/Understanding: accurately represents the thoughts, positions, and arguments of other people.

Commented [T017]: Argument Form: includes a reply to the criticism showing why it fails

Commented [T018]: Content/Understanding: body of reasons consistently relate back to and directly support the thesis. 
coffee instead of saving a human life, and that she is morally praiseworthy for doing so. Singer argues that it is indeed morally wrong to not give up that cup of coffee; it is morally optional or generous but one's moral obligation. Might this mean that one has to spend every waking hour maximizing utility? Must one spend oneself into poverty just to comply with the standard? Singer does argue that marginal utility — the point at which one is made as bad off as those she would help—is the right, if very strong standard. Singer recognizes this standard is so high that most people will walk away altogether rather than fail to meet it. To this end, he suggests a lower standard, or "moderate version" that exchanges moral comparability for "moral significance" (271).

Globalization has shrunken the world and, at the same time, increased our moral obligation. Modern technology has made it possible to instantly reduce suffering for people all over the globe. By tying our moral duty to our ability to prevent suffering without placing ourselves in a similar position, Peter Singer establishes a high moral bar. Indeed, it is higher than most people are likely to jump. What is clear, is that every consumer decision is tied directly to one's moral duty. This is an overwhelming prospect, but once it is known, ignoring it is morally wrong.
Commented [TO19]: Content/Understanding: defines technical terms

Commented [TO20]: Argument Form: includes a brief conclusion summarizing the argument. 


\section{Works Cited}

Singer, Peter. "Famine, Affluence, and Morality." Exploring Ethics: An Introductory Anthology 4e, edited by Steven M. Cahn, Oxford University Press, 2017, 264-273.

Mill, John Stuart. Utilitarianism. 1863. MacMillan, 1957.
Commented [TO21]: Professionalism: follows all instructions and meets all requirements. 


\section{SAMple Paper 2: The B-PAPer}

\section{A Student Aiming for a B}

Ethics Class

Mr./Mrs. Who is Teaching the Class

\section{Peter Singer and Charity}

Many people in the poorest areas of the world die every year from things like starvation and disease. At the same time, lots of people in the United States spend money on things they don't need, such as fancy clothes or expensive vacations. Peter Singer is a philosopher who thinks that these rich people should most of their extra money to help save the lives of the less fortunate. I think that he is partially right, but I don't agree with him entirely.

In his article, Singer begins with the assumption that "suffering and death from lack of food, shelter, and medical care are bad" (CITE XXX). He then goes on to write that:

My next point is this: if it is in our power to prevent something bad from happening, without thereby sacrificing anything of comparable moral importance, we ought, morally, to do it. By 'without sacrificing anything of comparable moral importance' I mean without causing anything comparably bad to happen, or doing something that is wrong in itself, or failing to promote some good, comparable in significance to the bad thing that we can prevent. (CITE XXX)

He concludes that, if this principle "were acted on, even in its unqualified form, our lives, our society, and our world would be fundamentally changed" (CITE XXX).

To under how he gets to this conclusion, we need to understand Peter's argument. His basic idea is that we should help people who need it, just as long as doing so doesn't hurt us worse than any person it might help. He gives the example of a seeing baby drowning. He thinks that, if you could save a baby from drowning in a pool, you should do it, even if this meant getting or shoes wet, or being late for an appointment. He compares this drowning baby to the sorts of children that you could save by donating to charity. He argues that there is no difference between the two 
cases. After all, the cost of your helping one of these children would likely be no more than the cost of stopping to help the child in the pool. If you agree that it is the right thing to save the drowning baby, then you should give to charity as well.

There are many good arguments against Singer. For example, the drowning baby is right in front of us, while the babies helped by the charities live thousands of miles away. Also, there are many people who could give to charity, while only you could save the baby. Also, the charity might not be effective one, since maybe giving money to charity now will only cause more problems down the line, since it will cause a population explosion. Singer has answers to all of these arguments, and he basically says that none of them actually make it $\mathrm{OK}$ for you to spend money on yourself when you know that you could help save somebody's life.

He makes the point that his ideas are supported by many religions. For example, the Christian idea that you should "love your neighbor as yourself" seems to fit with Singer's claim that we shouldn't put our own well-being ahead of the well-being of others.

In my opinion, Singer has some good points. I think that we should definitely give a little more money to charity, since we don't need it nearly as much as other people do. However, I don't think we should have to give to the point where we wouldn't have anything left to spend on ourselves. This is because I think this would simply be too much for most people. For example, I think a lot of people wouldn't be able to find the motivation to do things like go to work or go to school unless they thought that they would be able to make a better life for themselves and their families in some way. And part of having a better life means being able to spend money on "luxuries," like books, gifts for children, and vacations.

In contrast to Singer, I agree more with Susan Wolf, who thinks that we don't all need to try to be moral saints, but also need to take time to develop other areas of our lives. She thinks that moral saints would miss out on many valuable things in life, such as the chance to develop talents in things like art or athletics. This is also backed up by the ideas of Immanuel Kant, who argued that morality required only that we avoid treating other people as mere means, as opposed to maximize their happiness.
Commented [BS28]: Content: This gets the basic idea across, but doesn't lay out the arguments' structure with as much care as it might. What exactly are Singer's premises? And how do they relate to his conclusion?

Commented [BS29]: These might all be good objections to Singer. However, it would be much better to choose ONE of these arguments against Singer, and explain it in much greater depth.

Commented [BS30]: Clarity of thought: As a rule of thumb, avoid writing things like "I think/believe" or "in my opinion." Instead, simply state whatever it is you want to say, and then provide reasons for it.

Commented [BS31]: Again, avoid phrases such as "in my opinion.."

Commented [BS32]: Inference/Reasoning: OK, but why does Wolf believe this? And why should Singer agree? You need to take the time to explain this in more detail, and then consider how Singer might respond.

Commented [BS33]: Whenever you use technical terms (like "mere means"), you should take the time to explain what they mean in ordinary English. An example would help, as well. 
Peter Singer might criticize my argument by saying that this is a selfish point of view, and that I'm assuming my life is more important than the lives of other people. I would respond by saying that he doesn't really have a realistic view of human psychology, or how human society works. While his view seems like a good idea in theory, it couldn't actually work in the sort of extreme way he thinks it should. After all, even Singer doesn't give all of his money to charity.

In conclusion, Peter Singer argues that we should all give more money to charity. While I agree with this in part, I also think it's OK to keep some money to spend on ourselves.

\section{References}

Stephen M. Cahn. 2017. Exploring Ethics. $4^{\text {th }}$ edition. New York: Oxford University Press.
Commented [BS34]: Objectivity: This sounds too much like a personal attack on Singer. Try to rephrase (and expand on) this argument, so that its clear you are criticizing a particular premise of Singer's argument, and not Singer himself.

Commented [BS35]: Argument Form: A conclusion should do more than simply repeat your thesis. Instead, it should help the reader appreciate the importance of what you've done, and what you haven't (yet) done.

Commented [BS36]: Professionalism: While this reference section is OK, it would be better to cite Singer's/Wolf's articles in this book separately. In the body of the paper, more quotes and references to specific page numbers would be good. 


\section{SAMple Paper 3: The C-Paper}

\section{N. Prepared Student}

Ethics Class

Name of teacher

\section{Ethics Essay}

In my paper I will consider some of Singer's words when he says, "If it is in our power to prevent something very bad happening, without thereby sacrificing anything of comparable moral significance, we ought to do it." I don't believe in his word ought, because ought means that it must, has to be done. I can understand if the word ought was replaced by should or could, because then the person decides if they want to do it or not. Singer brings up the situation of poverty to argue why he thinks everyone has the obligation to assist. I believe that one should help out but only when they can. In the situation of poverty, it isn't the individual's responsibility to assist the very poor. It just means that we should and many do agree that this is the right thing to do even if they help or not.

\section{Singer says "We ought to prevent something very bad from happening". But one person} can't prevent all absolute poverty by themself. Since poverty affects many people around the world, if you were the only one to do it, it wouldn't show but you have met your duty to help. Singer states that for those who follow this basis, must assist in all the possible situations. Also if

\section{Commented [37]:}

Professionalism: Specify which ethics class. Make sure that $\mathrm{Mr} / \mathrm{Mrs}$ is really the person's preferred title (as opposed to Dr./Instructor/Professor).

\section{Commented [38]:}

If you include a title, it should do more than indicate the general topic (as this one does). Instead, it should give the reader an idea of what you are arguing.

\section{Commented [39]:}

Content: Be sure to properly cite the source of the quote.

\section{Commented [40]:}

While the thesis makes clear that the writer disagrees with Singer's conclusions, she should also make clear how she will argue on behalf of this conclusion.

\section{Commented [41]:}

Content: Background on Singer's major arguments are missing. Criticisms of Singer's conclusions won't be persuasive if his arguments aren't laid out beforehand. 
you only helped one time, it doesn't count as being good, one must continue to assist. Singer says,

"... it is something that everyone ought to do". I believe that no one has to do it. It is their decision

if they want to or not. I think we can prevent some poverty, but I can understand that if someone

doesn't do it. It doesn't mean that it's their duty. Saving lives is not a duty, but something that one

will know that it is the right thing to help when they can. With the drowning child we know it's our

duty to help because the child is there in front of us.

Singer says you have to accept obligations and help out. If you don't then the consequences

will make you a bad person. For example, if one doesn't accept their minimal obligations (whether

it's extra money, extra time, etc...) to help the poor, then they are essentially allowing those to die, which is similar to killing. Singer believes that everyone has a responsibility to assist without giving up too much. I believe that some don't even have a minimal obligation to assist. An example is that there are people in developed countries who believe they can't even live up to the basic needs in their country. So, they don't worry about others that are living in poverty. We all know that any kind of poverty is bad. This sounds selfish but I don't want someone to tell me how much I should help out. I believe that I know how much I can do to help the poor when I can. Everyone has their own reasons why they make those decisions. For me, a basic need that is necessary for me to "live" in my country is education. It has and will continue to drain my money that I could use to save lives. But I know that when I'm settled, I will be able to use that money towards saving some lives.

I believe Singer is not right concerning our obligations. We all should assist the absolute poor but only when we can. Most of us are living more comfortably than the absolute poor and even if we were to give some wealth out, we'd still be able to support ourselves, but it really
Commented [42]:

Content: Because Singer's arguments haven't been made clear, it's uncertain what is being criticized here.

Commented [43]:

Professionalism: Citation? What does "it" refer to here?

Commented [44]

Reasoning: This doesn't add up to an argument. It only repeats the disagreement with Singer's conclusion.

Reasons need to be given for thinking that Singer is wrong about our duty to help.
Commented [45]

Reasoning: It's not clear how this paragraph relates to the previous paragraph. Is it meant to develop an argument against Singer's conclusion? Begin a new argument against it?

\section{Commented [46]:}

Reasoning: Remember that the aim is to show that

Singer's arguments don't hold up, that his conclusion isn't true. The fact that you don't like hearing that you should help is no evidence against the argument that you should.

\section{Commented [48]:}

Content: Does what Singer argues conflict with this? It's very important to be sure that you are fairly presenting the views you are discussing. One sure sign that this isn't being done is making a critical claim that isn't actually in disagreement with what the author argues 
depends on who is willing to help. Just thinking about letting all the people out there die every day makes us feel as though we are murderers, but in the other hand you are responsible for yourself and not others. We're not murderers; we're doing what's best for us first. Everyone has the right to live as they wish and determine who they want to be.
Commented [49]:

Reasoning: Here again is a claim denying the truth of

Singer's conclusion without giving any reason for

thinking he's wrong. Always make sure to support claims with good reasons. 